Revista aSEPHallus de Orientação Lacaniana

Núcleo Sephora de Pesquisa sobre o Moderno e o Contemporâneo

ISSN 1809 - 709 X

\title{
O modelo e o exemplo na nosologia psicanalítica
}

Antonio Teixeira

Professor adjunto / UFMG (Minas Gerais, Brasil)

Doutor em Psicanálise / Universidade de Paris VIII (Paris, França)

Mestre em Filosofia / UFMG (Minas Gerais, Brasil)

Médico / UFMG (Minas Gerais, Brasil)

E-mail: amrteixeira@uol.com.br

Resumo: Diversamente do modelo nosológico que opera com um saber sobre a patologia do indivíduo, o recurso ao exemplo nos auxilia a pensar a condução clínica como uma prática guiada pelo saber construído pelo próprio sujeito em sua experiência de vida. É por isso que no lugar da simplificação homogênea do modelo, valemo-nos do exemplo como chamado para fazer a mesma coisa de forma diferente, no sentido em que uma situação clínica pode ser tomada como paradigmática para se pensar o que cada caso comporta de absolutamente inédito.

Palavras-chave: psicanálise, nosologia psicanalítica, classes, inclassificável.

The model and example in psychoanalytic nosology: Unlike the nosological model that operates with a knowledge about the pathology of the individual, the use of example helps us to think about clinical conduction as a practice guided by the knowledge built by the subject himself in his life experience. That is why, instead of the homogeneous simplification of the model, we use the example as called to do something differently in the sense that a clinical situation can be taken as paradigmatic to think about what is absolutely unheard of in each case.

Keywords: psychoanalysis, psychoanalytical nosology, classes, unclassifiable.iable.

Le modèle et l'exemple en nosologie psychanalytique: Contrairement au modèle nosologique qui utilise une connaissance de la pathologie de l'individu, l'utilisation de l'exemple nous aide à réfléchir à la conduction clinique en tant que pratique guidée par la connaissance construite par le sujet lui-même dans son expérience de vie. C'est pourquoi, au lieu de la simplification homogène du modèle, nous utilisons l'exemple comme appel à faire la même chose différemment dans le sens où une situation clinique peut être considérée comme paradigmatique pour réfléchir à ce que chaque cas comporte $\mathrm{d}^{\prime}$ absolument inédit.

Mots-clés: psychanalyse, nosologie psychanalytique, classes, inclassable. 


\section{O modelo e o exemplo na nosologia psicanalítica}

Antônio Teixeira

A abordagem das classes diagnósticas em psicopatologia exige, de nossa parte, uma precaução particular, uma vez que nesse campo o diagnóstico altera o prognóstico. O estigma produzido pelo diagnóstico não raro modifica a evolução da enfermidade, posto que o próprio curso de uma patologia mental encontra-se vinculado à expectativa que o paciente mantém em relação ao Outro que assim o nomeia. Seja na patologia do sujeito histérico, que faz enigma do próprio sintoma para suscitar o desejo do Outro; seja na tarefa interminável do obsessivo que visa encontrar, na submissão às regras do Outro, a garantia do seu reconhecimento; seja, ainda, na perplexidade do sujeito psicótico, às voltas com as exigências obscenas do Outro que a ele retornam como vontade de gozo, a expectativa gerada pelo diagnóstico que altera o prognóstico se formula numa mesma pergunta: O que o Outro espera de mim?

Se podemos, então, falar dos efeitos de estigmatização causados pela nomeação diagnóstica, é porque por um bom tempo a resposta clássica à questão significante da expectativa do Outro se dava pela via do signo. Surgido no século XV como termo religioso referido às chagas de Cristo, o substantivo stigmata veio denotar, a partir do século XVII, a ideia do castigo que inscreve sobre a pele a marca da infâmia que marca a percepção do sujeito pelo Outro social. Será somente mais tarde, a partir do final do século XIX, que a conotação moral desse termo será cientificamente neutralizada, passando a receber, no vocabulário médico, o valor puramente semiológico do sinal clínico sobre o qual se estabelece o diagnóstico de uma patologia.

Sabemos que a percepção de um fenômeno perde sua conotação moralizante quando esse mesmo fenômeno se torna objeto do discurso da ciência. Mas se o estigma difamante da doença pôde ser neutralizado no campo da medicina científica, por que, então, o opróbrio permanece ainda ligado ao sujeito diagnosticado como portador de patologia mental? Teríamos, então, que aguardar pela ocasião em que a objetivação científica do fenômeno mental viria neutralizar o efeito difamante ocasionado pelo diagnóstico psicopatológico, momento, enfim, em que, no lugar de nos referirmos ao sujeito depressivo, falaríamos de um caso de serotoninopenia, e em vez de psicose delirante, diríamos se tratar de hiperdopaminemia? Pelo tom visivelmente irônico da pergunta, já se adivinha que nossa resposta é negativa.

$\mathrm{Na}$ verdade, não é por uma insuficiência circunstancial do saber científico que o diagnóstico da patologia mental resiste a ser abordado cientificamente. É necessário antes de tudo entender que se a patologia mental pode num certo momento ser tomada enquanto objeto do saber médico, essa objetivação dependeu de um gesto eminentemente moral, não cientifico, por meio do qual a ciência veio recusar, em sua fundação cartesiana, a possibilidade de coexistência entre loucura e racionalidade.

Racionalidade e loucura nem sempre foram dimensões excludentes: havia até o início da 
era clássica, esclarece Foucault, uma relação reversível na qual a loucura se revelava como verdade oculta da razão. Se Aristóteles podia aproximar, no célebre problema XXX, o homem de gênio da melancolia, é porque a loucura podia ser vista, no período anterior à emergência da ciência moderna, como uma espécie de paroxismo da razão. Seja como consciência trágica, nas telas de Bosch e de Bruegel, seja como crítica irônica, no famoso Elogio de Erasmo de Rotterdam, esse topos da razão louca, lugar retórico da suspeita de que a construção racional do mundo pudesse, no fundo, ser ensandecida, chegou a ser tão disseminado que não se podia isolá-lo num espaço definido. Para que a loucura fosse objetivada, adquirindo seu lugar perceptivo próprio, foi necessário um gesto que a desenredasse violentamente do pensamento.

A mais sutil loucura é feita da mais sutil sabedoria, escrevia o ensaísta Montaigne no século XVI. Se a loucura ainda podia habitar o saber para o ceticismo quinhentista de Montaigne escritor de ensaios que se recusava a construir sistemas, por duvidar justamente de toda base racional do pensamento -, ela será radicalmente excluída pela filosofia inaugurada por Descartes no século XVII. Ao fundar seu novo sistema de pensamento sobre o alicerce racional indubitável do cogito, Descartes lança as bases da ciência pelo mesmo gesto que reduz a loucura ao silêncio. Ao estabelecer, em sua origem, que a natureza pode ser objetivamente conhecida, em sua estrutura matemática, o pensamento científico moderno organizou a conviç̧ão de que a razão não é intrinsecamente louca, que o problema do engano e do erro não se encontra na racionalidade concebida nela mesma, mas somente no seu uso indisciplinado.

Privada de sua antiga dignidade de consciência trágica para ser tratada como simples fonte de erro, no termo de um longo processo que a separou da razão, a loucura deixará de ser tomada como experiência de lucidez. A figura do filósofo louco desaparece. Diante da pergunta sobre o que o Outro espera de mim, a ciência agora responde que do louco não se deverá esperar mais nenhum pensamento.

Nesse sentido, embora ciência e segregação moral sejam práticas discursivas estruturalmente distintas, não podemos deixar de nos perguntar por que discurso científico e prática segregativa até hoje se dão as mãos no campo da patologia mental. Se o discurso ciência, ao ser convocado no domínio da psicopatologia, termina frequentemente por incorrer nessa infame aliança com as práticas segregacionistas, é na medida em que todo esforço de objetivação da patologia mental se coloca a serviço daqueles que visam privar o louco do valor de sua palavra. Ao definir alguém como "alienado", o discurso segregacionista apoia-se na autoridade científica para silenciar sua fala, condenando-o ao destino das subjetividades desacreditadas.

Seja qual for, portanto, o nível de êxito ou de dificuldade em tratar cientificamente o fenômeno mental, o que a ciência moderna estabelece axiomaticamente, em sua fundação, é que a loucura não pensa, ela nada tem a dizer. Dali se explica o fato de que toda a psicopatologia constituída ao longo do século XIX pôde se valer de padrões normativos de classificação que, embora desprovidos de verdadeira metodologia científica, comungavam com a ciência o gesto de 
eliminação da palavra do alienado mental, em nome de um saber que visava, em última instância, controlar os indivíduos mediante sua representação nas classes sociais definidas pelo Estado.

O problema é que normalmente as classes se constituem em torno de uma representação atributiva destacada por um discurso, como no caso da presença de glândulas mamárias na constituição da classe dos mamíferos ou de incisivos superiores pronunciados no caso dos roedores. Mas as classes cujos elementos são sujeitos não se encontram fundadas sobre nenhuma propriedade empiricamente representável, no sentido que existe apenas o efeito de alienação produzido e reafirmado por um gesto de nomeação (Milner, 1983, p.110). Se o diagnóstico então altera o prognóstico, é na medida em que as classes, assim constituídas, produzem efeitos sobre os seres que nelas se representam. Mas com a importante ressalva de que o sujeito não se deixa alienar inteiramente nessa representação. Há sempre algo de sua apresentação que não se deixar representar, um resto, inerente ao sujeito, que resiste a ser assimilado pelas propriedades representativas do indivíduo.

O que diferencia, nesse sentido, a psicanálise do contexto que a precedeu, foi o fato de considerar a causa do desejo como resto irrepresentável das classificações. Ao ser convocada a intervir como uma terapêutica, a psicanálise não procede, como chegou a afirmar Foucault, em continuidade com as práticas de controle que visavam ajustar o indivíduo à unidade de sua representação (Foucault, 1996, p. 122). Ela antes surge como resposta ao sofrimento gerado pela dificuldade que experimenta o sujeito em se adequar à classe que o representa, ao se haver com algo da exigência pulsional que o divide, ou seja, que não se deixa integrar em sua unidade representativa de indivíduo. Não por acaso ela deve sua origem à consideração clínica, por parte de Freud, da loucura histérica no que ela tinha de mais desconcertante para o saber classificatório: doença inclassificável, por excelência, a histeria se modifica constantemente com relação a ela própria, colocando a perder todo esforço de objetivação da patologia mental por sua capacidade de exibir, de maneira aparentemente aleatória, os sinais clínicos de todas as classes diagnósticas.

Para decifrar o enigma da histeria, objetivá-la, no nível pretensamente científico de uma psicologia dos fenômenos mentais, não nos leva muito longe; é preciso, antes de tudo, escutar o que o sujeito histérico tem a dizer. Ao ouvir suas primeiras pacientes histéricas, Freud nota de saída que a cisão patológica dos conteúdos de consciência não derivava de uma falha de síntese, como se formula na hipótese objetivante de Pierre Janet, mas antes de um ato de vontade inconsciente do sujeito que dela não quer saber. Se não passou desapercebido a Freud, conforme observa P. Tavares, a derivação do léxico alemão Kränkung, que em alemão significa literalmente "ofensa", para o adjetivo Krank (doente), é por ele notar, na etiologia do padecimento mental, a pressão de um desejo cuja satisfação é interpretada como uma ofensa que o sujeito decidiu esquecer (Freud, 2016, p. 194). A solução histérica (e não sua deficiência inata, como diria uma vez mais $P$. Janet) consiste em transpor o fator libidinal dessa satisfação incompatível para o corpo, na forma da conversão, com vistas a desembaraçar a unidade egoica do elemento 
desarmônico, que passa assim a parasitar uma função corporal onde se forma o núcleo de outro grupo psíquico, inacessível à consciência.

Não é apenas na loucura histérica que Freud identifica a inadequação entre a apresentação dividida do sujeito e a unidade em que ele se representa. Ele a identifica igualmente na loucura obsessiva, que tende a ser tanto mais grave quanto mais normal o indivíduo busca ser. No lugar de transpor o fator libidinal incompatível para o corpo, a defesa consiste agora em manter sua representação mental distante das associações do pensamento consciente, fazendo com que o afeto dali desligado venha habitar ideias aparentemente absurdas que parasitam a consciência. Mas há também, para além da loucura histérica e da loucura obsessiva, a loucura propriamente dita, ou seja, a loucura psicótica onde o fator pulsional recebe um destino diverso. Em vez de ser enquistado num pensamento parasita ou transposto para algum componente somático de valor simbólico, o elemento recusado se encontra de tal modo enredado na realidade externa que o Eu termina por dela se desligar. As autorrecriminações do obsessivo e a satisfação impedida da histérica se deslocam, via projeção, para os sentimentos delirantes de desconfiança e perseguição, situando no campo do Outro o excesso pulsional incompatível com a representação do sujeito.

É evidente que a apresentação esquemática desses três modos de solução nem de longe faz justiça à riqueza de detalhes que Freud desenvolve. Queremos com esse esquema somente enfatizar que a inteligibilidade da patologia mental se constitui na medida em que Freud abandona a perspectiva objetivante do saber científico que silencia a palavra do louco, para escutar o que seu paciente tinha a dizer. Mas o que dizer, então, das classes diagnósticas que a psicanálise parece convocar, ao se referir ao sujeito como histérico, obsessivo ou psicótico? Não estaria a psicanálise retomando o princípio mesmo de representação classificatória que tanto questionamos, no momento em que estabelece, a partir das nomeações colhidas no saber psiquiátrico, as classes diagnósticas de sua nosologia clínica?

Na verdade, não. Para me fazer explicar, eu gostaria de evocar mais uma vez a lembrança de um chefe de serviço hospitalar em psiquiatria que se acreditava psicanalista, o qual tomado de ímpeto gerencial, propôs dividir o setor em alas distintas, destinadas a agrupar separadamente os pacientes obsessivos, histéricos e psicóticos e assim por diante. Se isso nos faz rir, é porque intuitivamente sabemos que as nomeações diagnósticas da psicanálise não convocam nenhum tipo de agrupamento ou universo de casos. Elas somente nomeiam, conforme propõe J.-C. Milner, a maneira obsessiva, histérica, ou psicótica que tem um sujeito de ser inagrupável, dessemelhante de todo outro (Milner, 1983, p.118-119). A vacilação da clínica analítica, que primeiramente orienta a apresentação do caso pela necessidade da representação no diagnóstico, para em seguida retornar à singularidade do caso no que ele se apresenta de radicalmente diverso, longe de ser acidental, é o que verifica a sua própria essência. Por essa vacilação se atesta o sujeito que excede, em sua apresentação cindida, a toda classificação representável mobilizada por nossa nosologia clínica. 
É nessa perspectiva que Jean-Claude Milner nos propõe pensar as classes diagnósticas da psicanálise como classes paradoxais. Quando sugerimos, por exemplo, durante uma supervisão clínica, diante da queixa de insatisfação de uma determinada paciente, que devemos talvez pensar num caso de histeria, isso não quer dizer que estamos nos referindo à classe dos histéricos como uma coleção de pessoas insatisfeitas. Não existe para nós uma coleção de casos que funcionaria enquanto premissa universal, na dedução de um silogismo clínico do tipo modus ponens: todos os insatisfeitos são histéricos, $x$ é insatisfeito, logo x é histérico. Sabemos que existem sujeitos insatisfeitos que não são necessariamente histéricos. O que importa, propriamente, captar, é menos a queixa de insatisfação de uma demanda do que o paradoxo do sujeito que inconscientemente requer a insatisfação para se manter desejante. Pois o que escapa ao universal é justamente o modo singular de requisição dessa insatisfação que o mantém no horizonte do desejo. Ela assim se expressa seja como desejo pelo caviar, no sonho da bela açougueira, seja na pseudociese de Anna O., em sua transferência não suportada por Breuer, ou ainda, para retomar um personagem da literatura, no olhar longínquo de Emma Bovary que busca, em sua insatisfação permanente, escapar da miséria espiritual de sua existência provinciana, sem que se possa determinar a coleção de casos em que se esgotam suas manifestações.

Importa notar que embora não se possa alcançar pela via indutiva, no repertório exaustivo dos exemplos, a determinação universal de uma classe diagnóstica, ainda assim, a cada vez que discutimos um caso acende em nosso pensamento a recordação dos exemplos da clínica e da literatura. Não raro falamos, por exemplo, do bovarismo para nos referir ao comportamento de uma histeria, e toda vez que interpelamos um caso de neurose obsessiva, procuramos saber quem ocupa, na história do paciente, a posição do capitão cruel. Isso nos leva a pensar que em vez de proceder verticalmente pela indução que vai da parte ao todo, visando alcançar o universal da classe nosológica, para em seguida ir do todo à parte, no sentido de estabelecer dedutivamente o diagnóstico clínico, fazemos na verdade um movimento horizontal que vai da parte à parte, valendo-nos de um exemplo particular como referência paradigmática para pensar o caso que nos ocupa.

Paradigma significa, literalmente, o que se mostra ao lado (paradeigma), o que serve de exemplo. A ideia de evocar essa temática não é para mim casual, pois tive nos dois últimos anos a sorte de acompanhar, como orientador, um excelente trabalho de pesquisa realizado no programa de pós-graduação em psicanálise da UFMG por Saulo Carvalho, que explorou a formulação do conceito de paradigma na obra de Thomas Kuhn e sua função operatória na clínica psicanalítica. A ideia que Saulo Carvalho (2019) ali desenvolve, é que existem situações em que o esquema ao qual nos referimos para pensar uma situação determinada depende, em seu uso concreto, menos da derivação de um conceito universal do que da experimentação dos casos particulares tomados como casos exemplares ou paradigmas. Isso faz com que a resolução de um problema particular, como se dá quando tentamos conduzir um caso clínico, longe de ser o resultado da aplicação de 
um saber previamente estabelecido, constitui ela mesma fonte de conhecimento.

Não por acaso Lacan dirá, em sua "Introdução à edição alemã dos Escritos", que embora não seja pródigo em exemplos clínicos, quando deles se serve é para elevá-los ao paradigma (Lacan, 2003, p. 554). Se é possível resolver problemas, como diz T. Kuhn, referindo-se a soluções anteriormente alcançadas (Kuhn, 1998, p. 232), o paradigma seria o exemplo compartilhado cuja exibição nos permite pensar o caso concreto que tentamos solucionar, porquanto reúne tanto os aspectos estruturais determinantes para sua elucidação conceitual quanto os elementos singulares de sua ocorrência. Isso se dá tanto do ponto de vista histórico-sociológico, quando tomamos o panopticum de J. Bentham como construção paradigmática da sociedade disciplinar, quanto do ponto de vista clínico quando nos referimos ao caso do "Homem dos ratos" como figura exemplar da neurose obsessiva. Mas se o recurso ao paradigma interessa particularmente à clínica psicanalítica, é na medida em que a dimensão do sujeito com o qual temos que nos haver não se deixa conceber formalmente como uma categoria derivada do universal. $O$ sujeito, enquanto resposta do real, se manifesta justamente como efeito "que desloca o indivíduo da espécie, o particular do universal, ou o caso da regra" (Miller, 2006, p. 30). Dali resulta, entre outras coisas, tanto o desinteresse da psicanálise em relação ao repertório estatístico de múltiplos casos, quanto a importância que ela atribui à discussão detalhada do caso único.

É instrutivo lembrar, a esse respeito, que o mesmo Lacan, que em sua tese de doutorado expôs minuciosamente o caso Aimée como paradigma da paranoia de autopunição, tenha recorrido ao exemplo biográfico literário de James Joyce como meio para pensar o que vem a ser a solução subjetiva que dispensa a referência falocêntrica. $O$ fator que mobiliza o recurso ao caso paradigmático é a ideia, amplamente desenvolvida por Saulo Carvalho (2019), de que o exemplo já contém nele mesmo a estrutura ao qual se encontra referido. Isso se ilustra particularmente no uso, por parte do homem dos ratos, da locução "por exemplo" (zum Beispel), referida ao temor de algo ruim que Ihe poderia acontecer, quando se via tomado pelo desejo luxurioso de ver moças despidas. Poderia acontecer, por exemplo, diz ele, que seu pai deveria morrer. Freud nesse ponto se detém, convencido de que o exemplo dado por seu paciente já é uma neurose obsessiva completa, o organismo elementar cujo estudo - e somente ele - nos proporcionará a escala para medir a organização da enfermidade presente (Freud, 1996, p. 130). É nesse sentido que o paradigma nos permite suspender a explanação exaustiva, ao nos revelar a estrutura em seu elemento mínimo.

A ideia de se orientar pelo exemplo paradigmático não deve, contudo, conduzir-nos a tomá-lo como modelo heurístico de um universo de casos. Cabe antes distinguir a orientação pelo modelo da via do exemplo, enfatizando que o primeiro se aplica como uma simplificação violenta da realidade, uma abstração universal que tenta tornar seu objeto conforme a seu modo de representação numa realidade discursiva, como acontece no momento em que se tenta estabelecer um padrão de tratamento de acordo com o protocolo determinado pelo diagnóstico de 
uma patologia. Quando isso não acontece, a culpa é do paciente que não seguiu as regras do tratamento clínico, ou do país endividado que não adotou as normas de saneamento econômico impostas pelo FMI. Mas quando nos orientamos, por outro lado, pela via do exemplo, em vez de tentarmos tentar impor ao real uma representação abstrata da realidade, operamos com algo que já se apresenta no nível, por assim dizer, de uma realidade provisória, no sentido em que nos servimos de elementos já dados na situação presente, ao mesmo tempo que os destinamos a uma função distinta daquela que prescreve o seu uso ortodoxo.

Retomando, então, uma terminologia cara a Lévi-Strauss, diríamos que a referência ao modelo se aproxima da atividade do engenheiro, que opera com objetos idealmente concebidos para a função padronizada de seu projeto, ao passo que o recurso ao exemplo estaria mais próximo ao trabalho do bricoleur, que inventivamente desloca os objetos que tem à mão de sua função original e os converte em gambiarras, no sentido em que se vale, pela via do improviso, de modos imprevistos de utilização. Assim como o bricoleur se serve de uma caneta enquanto instrumento perfurante ou de uma enciclopédia como escada para trocar uma lâmpada, o psicanalista recorre aos romances de Flaubert e James Joyce como exemplos paradigmáticos para pensar a histeria e a solução psicótica, a partir de aspectos alheios ao que normalmente se espera do trabalho de crítica literária, sem esgotar a possibilidade deslocada de seu uso. Pois é pela impossibilidade de completar seu projeto, no sentido em que completá-lo seria torná-lo integralmente conforme ao ideal que preside o seu uso, que o bricoleur (e o psicanalista, se LéviStrauss assim o permite) sempre ali colocam algo de si (Lévi-Strauss, 2008, p.32).

Interessante notar, no que tange ao ideal de uma ciência biológica que se busca impor à clínica psiquiátrica, que a própria evolução da vida que lhe serve de modelo antes procede por bricolagens, e não por formas ideais. A configuração anatômica do organismo é fiel ao princípio do bricoleur, observa Viveiros de Castro (2017), ao comentar a negociação biomecânica que preside a formação de nossa coluna vertebral na transição da condição quadrúpede à postura ereta. Se nos importa, assim, considerar a distinção entre modelo e exemplo, tal como Viveiros de Castro a desenvolve a partir de sua leitura de "O pensamento selvagem", é na medida em que buscamos conceber uma visão não normativa da nosologia psicanalítica que leve em conta o que o sujeito que tem a dizer de sua experiência. Diversamente do modelo nosológico que opera com um saber sobre a patologia do indivíduo, o recurso ao exemplo nos auxilia a pensar a condução clínica como uma prática guiada pela consideração de elementos que se apresentam concretamente na história e no saber construído pelo próprio paciente. É por isso que no lugar da simplificação homogênea do modelo, valemo-nos do exemplo como chamado para fazer algo diferentemente igual, no sentido em que uma situação clínica pode ser tomada como paradigmática para se pensar o que cada caso comporta de absolutamente inédito. 


\section{Referências bibliográficas}

Carvalho, S. O caso paradigmático e a nosologia estrutural, 2019 (no prelo).

Foucault, M. $A$ verdade e as formas jurídicas. RJ: Nau, 1996.

Freud, S. Neurose, psicose e perversão. BH: Autêntica, 2016.

Freud, S. Notas sobre um caso de neurose obsessiva. Edição Standard Brasileira das obras completas, vol. X. Rio de Janeiro: Imago, 1996.

Kuhn, T. A estrutura das revoluções científicas. SP: Perspectiva, 1998.

Lacan, J. Outros escritos. RJ: Jorge Zahar, 2003.

Lévi-Strauss, C. O pensamento se/vagem. S. P.: Perspectiva, 2008.

Miller, J.-A. A arte do diagnóstico: o rouxinol de Lacan. In: Curinga, n. 23. Belo Horizonte: EBP, pp. 15-33.

Milner, J.-C. Les noms indistincts. Paris: Seuil, 1983.

Viveiros de Castro, E. (2017). O modelo e o exemplo. Conferência inédita. UFMG. (Produtor).

(2017). Ciclo UFMG, 90: Desafios Contemporâneos. Acessível in: https://www.youtube.com/watch?v=_PfE54pj1wU

Citacão/Citation: Teixeira, A. (mai. 2018 a out. 2018). O modelo e o exemplo na nosologia psicanalítica. Revista aSEPHallus de Orientação Lacaniana, 13(26), 81-89. Disponível em www.isepol.com/asephallus. Doi: 10.17852/1809-709x.2019v13n26p81-89.

Editor do artigo: Tania Coelho dos Santos.

Recebido/Received: 03/01/2019 / 01/03/2019.

Aceito/Accepted: 12/03/2019 / 03/12/2019.

Copyright: (C) 2019 Associação Núcleo Sephora de Pesquisa sobre o moderno e o contemporâneo. Este é um artigo de livre acesso, que permite uso irrestrito, distribuição e reprodução em qualquer meio, desde que o autor e a fonte sejam citados/This is an open-access article, which permites unrestricted use, distribution, and reproduction in any medium, provided the author and source are credited. 